\title{
Total Clearance Observed by Fraction Dose Normalized by Dose
}

National Cancer Institute

\section{Source}

National Cancer Institute. Total Clearance Observed by Fraction Dose Normalized by

Dose. NCI Thesaurus. Code C92400.

The observed total body clearance for extravascular administration based on the fraction

of dose absorbed and divided by the dose. 